\title{
ESTRATÉGIAS EM JOGO: A SURPRESA DO GOL CONTRA NO FUTEBOL PARANAENSE
}

\author{
Luiz Demétrio Janz Laibida ${ }^{1}$
} Sylvana Kelly Marques da Silva ${ }^{2}$

\section{Resumo}

Inquieta-nos a atenção ínfima dos cientistas sociais brasileiros a uma das principais manifestações da cultura nacional: o futebol. Por isso, das várias portas de entrada para se pensar os múltiplos sentidos que configuram os jogos de poder na esfera social, suas formas de cruzamento e interação, neste texto damos atenção ao futebol. Evidenciamos as configurações do poder no interior dos quatro clubes de futebol na capital do Paraná por meio do mapeamento dos seus principais dirigentes e suas relações sociais com as elites locais. O objetivo é apontar como a estrutura nuclear do jogo de futebol concebe o funcionamento da sociedade enquanto resultado de incontáveis e variados afrontamentos, transgressões e dispersões de acontecimentos que se sobressaem em meio às disputas engendradas nesse espaço em que o tradicional cede lugar ao novo; uma vez que os dirigentes dos clubes em questão estão perdendo os seus espaços para novos entrantes. A discussão arrola-se a partir das contribuições de Michel Foucault, localizada no modo como o autor abarca as dinâmicas sociais e históricas. De modo mais direto, fornecemos instrumentos teóricos e metodológicos para se avançar nos estudos da sociologia do esporte, a partir dos estudos da elite do futebol.

Palavras-chave: Futebol, Curitiba, Sociedade, Configurações de poder.

\begin{abstract}
We are concerned about the tiny attention of Brazilian social scientists to one of the main manifestations of national culture: soccer. Therefore, from the various entrance doors to think about the multiple senses that configure the power games in the social sphere, their forms of

\footnotetext{
${ }^{1}$ Doutor em Sociologia pela UFPR, Pós doutorando em Sociologia pela mesma instituição, Professor de Sociologia do Quadro Próprio do Magistério do Estado do Paraná.

${ }^{2}$ Doutora em Sociologia pela UFRN, Professora Adjunta e Coordenadora no curso de Turismo pela UFMA.
} 
crossing and interaction, in this text we pay attention to football. We highlight the configurations of power within the four soccer clubs in the capital of Paraná through the mapping of their main managers and their social relations with local elites. The goal is to point out how the nuclear structure of the soccer game conceives the functioning of society as a result of countless and varied affronts, transgressions and dispersions of events that stand out amid the disputes engendered in this space in which the traditional gives way to the new, since the managers of the clubs in question are losing their spaces to new entrants. The discussion takes place from the contributions of Michel Foucault, located in the way the author encompasses social and historical dynamics. More directly, we provide theoretical and methodological instruments to advance in the studies of sports sociology, based on the studies of the football elite.

Key Words: Soccer. Curitiba. Society. Power configurations.

\section{Introdução}

Este texto nasce a partir de uma pesquisa mais ampla que direcionou a tese: "Raposas e outsiders no futebol paranaense: um estudo sobre relações de poder e genealogia". É uma tese empreendida em decorrência da inquietação em relação à negligência dada ao futebol, um dos mais importantes elementos da cultura deste país, nas ciências sociais, principalmente, na sociologia. Nela, assinalam-se por um lado as dificuldades em pesquisar o tema, tendo em vista a carência de suportes bibliográficos; por outro lado, em sinal da carência aludida, demarca que as contribuições, por mais modestas que sejam, concorrem, sobremaneira, para a construção de um estudo crítico sobre o tema. Acreditamos que essa lacuna se deve, também, ao fato de as grandes tradições sociológicas estarem por longo tempo envolvidas no estudo do processo fundador da sociabilidade na cultura ocidental, o trabalho. Nesse enquadramento, era óbvio que os cenários que circunscrevem o jogo de futebol apareceriam como uma questão periférica, fora das estruturas fundamentais da cultura ocidental.

Nesse primeiro estudo, analisamos as relações de poder e sua reprodução por intermédio da estrutura genealógica da elite envolvida com o campo futebolístico. Agora, ousamos mergulhar em novas searas teóricas, compreender as empirias com base no escopo foucaultiano, como potências dinâmicas e transformadoras de sentidos. Tendo isso em consideração, distanciamo-nos das concepções sociológicas que apontam os sistemas de submissão ao se debruçarem sobre a reprodução do poder e nos rendemos à genealogia enquanto um meio 
constante de problematizar as evidências. Assim, os mais diversos tipos de acontecimentos relacionados e conduzidos por um fio que lhes dariam uma origem e uma espécie de evolução são questionados. E, das várias possibilidades de se pensarem os múltiplos sentidos que configuram os jogos de poder na esfera social, suas formas de cruzamento e interação, apontamos, mais uma vez, para o espaço que circunscreve o empoderamento na esfera do futebol.

De modo profícuo, ainda, fornecemos instrumentos teóricos e metodológicos para se avançar nos estudos da sociologia do esporte, com base nos estudos de empoderamento por meio do futebol. A reduzida literatura sobre o jogo do futebol, em sua maioria, traz uma visão idealizada da atividade, constituindo-a enquanto um evento na dinâmica social, com suas conquistas e seus heróis ou mesmo por seu papel civilizador no processo de modernização da sociedade (Huizinga, 2004; Corbin, 2001; Caillois, 1990). Entre outras abordagens, podemos citar o caráter integrador do jogo e o seu uso como ferramenta de redução das desigualdades sociais. Na década de 1990 a Universidade Estadual do Rio de Janeiro - UERJ institucionalizou o Núcleo de Sociologia do Futebol, tendo sido a primeira universidade a se ocupar do assunto de maneira mais profícua.

Empiricamente assinalamos as configurações de poder no interior dos quatro clubes de futebol em Curitiba, capital do Paraná (Atlético, Coritiba, Paraná e J. Malucelli), por meio do mapeamento dos seus principais dirigentes e suas relações sociais com as elites locais. E observamos que indivíduos que estão à margem da perspectiva genealógica local, na periferia dos campos políticos e sociais definidos por essas elites, abarcam o poder no futebol contra uma lógica de dominação que parecia firmada pelo acesso às instituições sociais determinantes nesse espaço. Mesmo com menor poder de barganha, os engendramentos e as estratégias sociais permitem que novos agentes, como os empresários, entrem em cena, por intermédio de táticas que rompem com velhos paradigmas. É o gol contra, a surpresa em relação aos estudos que apontam que o Estado do Paraná se caracteriza por uma história em que a classe dominante, organizada por grupos familiares específicos, mantém sua hegemonia presente até os dias atuais.

Uma das pesquisas mais relevantes sobre esses aspectos é a do sociólogo Ricardo Oliveira (2001), em que destaca o Paraná como um dos estados onde a dominação dos grupos familiares é das mais expressivas, o que determina a construção de permanências no poder e estigmatiza o presente com relações arcaicas. Todavia, nesses estudos, a história que aparece com base na genealogia pode ser interpretada diante da afirmação de Foucault (1984, p.17), como "sistemas de submissão: não a potência antecipadora de um sentido, mas o jogo casual 
das dominações". A grosso modo o poder aparece como uma maquinaria de reprodução da ordem, como uma camisa de forças, como um processo contínuo, teleológico e evolucionista.

Com Foucault o objetivo é outro, ou seja, não mais o saber em busca de origens, representado em fato que se desenrola por meio de um núcleo gerador, porém, uma genealogia das relações de poder que surgem nas tramas sociais produzindo novos sentidos, práticas e lugares passíveis de serem habitados por diferentes indivíduos. É apontar como a estrutura nuclear do jogo de futebol concebe o funcionamento da sociedade enquanto resultado de incontáveis e variados afrontamentos, transgressões e dispersões de acontecimentos que se sobressaem em meio às disputas engendradas nesse espaço em que o tradicional cede lugar ao novo, uma vez que os dirigentes dos clubes em questão, como atestamos no Paraná, estão perdendo o seu espaço para novos entrantes.

\section{Astúcias, estratégias e indefinições no "jogo" do futebol}

Os jogos em si passaram tempos despercebidos nos escritos acadêmicos, na teoria de Friedrich von Schiller ganha centralidade em alusão às questões da educação e liberdade e, posteriormente, com Nietzsche o jogo se destaca com base em sua representação paradigmática. Nesse ínterim, a agonística que os jogos representam passa a ser tomada como fundamento epistemológico e ético da interpretação da vida social e da história humana. O jogo não está presente na obra de Foucault, mas apresenta uma dimensão nuclear em sua trajetória, nas palavras de Albuquerque Jr. (2004):

A obra de Michel Foucault não conta com qualquer título ou texto que aborde o tema do jogo. No entanto, a palavra jogo espalha-se por muitos dos seus escritos e figura em muitas de suas entrevistas e aparições públicas. No texto Nietzsche, a genealogia e a história (Foucault, 1984a, p.23), a palavra jogo aparece em diversas ocasiões, quando Foucault tentar diferenciar a maneira como, normalmente, os historiadores figuram o passado e a relação da história com ele, da forma como Nietzsche e, por extensão, o próprio Foucault, praticavam história e relacionavam-se com os relatos que constituem o que chamamos de memória. A palavra jogo não aparece aí apenas como metáfora, mas como forma de conceber o funcionamento da sociedade, de figurar como se passa a história, um modo de ver o mundo, de pensá-lo e relacionar as empirias e os conceitos.

De acordo com a abordagem colocada pelo autor fica explícito que a história se dá em meio a uma pluralidade de afrontamentos e eventos que pululam no percurso das contestações. Pensar a história é, então, pensar um espaço rugoso, volátil e potencial, é pensar como num jogo. É fato que a história do jogo de futebol ultrapassa o nosso objetivo, que diz respeito às 
formas de cruzamento, interação e estratégias que circunscrevem o empoderamento na esfera do futebol, em um específico campo. Mas a história do jogo de futebol dialoga transversalmente com nosso objetivo, uma vez que entendê-lo por meio das relações sociais de poder é atentarse que esse é ainda um modelo de representação das relações de luta, rivalidade, disputas, concorrências, emulações e interpretação da vida social e das dinâmicas culturais no Ocidente (LAIBIDA, 2016).

Em meio às astúcias humanas, estratégias e, também, indefinições, o jogo de futebol surge, no sul da Inglaterra, como um instrumento de controle das pulsões, destinado a disciplinar corpos e mentes, uma maquinária de produção de sujeitos treinados e hábeis, como um reflexo da sensibilidade adequada à ordem social burguesa. Visava, antes de tudo, manter os moços das public schools presos aos seus espaços de ensino no momento de recreio, afastando-os das ruas e das vadiagens e lhes ensinando o respeito pelas regras e códigos de valor. Essa perspectiva disciplinar caracteriza o esporte até o final dos anos de 1870. Difundido nos meios abastados, faz parte dos ritos de integração escolar, com base nos sistemas educativos da sociedade militar e da moral imperial destinado à aristocracia, o que destaca sua atribuição iniciática.

A partir da década de 80 do século XIX, o futebol com quase trinta anos de idade, abrese a novos atores, seu contorno aristocrático cede, para posterior desdém, espaço para a middle class. Seu caráter codificado e racional atua como estratégia de domínio e direcionamento de força das classes populares, um projeto de recreação racional, fincado no seio da classe média, que logo é, também, apropriado pelos trabalhadores. E, assim que é percebido como um meio de metamorfosear a cultura operária em uma cultura nacional, que não se limita mais aos operários, que passa a incidir no conjunto das categorias populares, sua difusão abole a clivagem geográfica inglesa. Desenvolve-se em diferentes portos, sendo propriedade de companhias marítimas britânicas, o que facilita sua exportação (CORBIN, 2004).

Para Roberto DaMatta (1982), cada sociedade tem o futebol que merece, pois nele é depositada uma série de questões e demandas que lhe são inerentes. Na América Latina o futebol se desenvolve, sobretudo, pela influência de viajantes ou técnicos e operários britânicos que foram atuar em obras ou viajantes que, após sua estada na Inglaterra, decidiram, ao retornar, implantar o jogo em seu país. Quando este chega ao Brasil, sua interação social é conflituosa, marcada por um veio elitista e racista, proibido a negros, mestiços e brancos pobres. Assim, o futebol brasileiro não representa apenas uma modalidade esportiva com regras próprias e técnicas e táticas sui generis; para além, é uma forma que a sociedade brasileira encontrou para expressar e extravasar sensibilidades distintas. No Brasil, alia-se e se antagoniza com as 
dinâmicas sociais correlatas às questões nacionais. Concomitantemente, distribui (oportunidades), inclui (massas desfavorecidas) e imprime autonomia (nacional, na política externa; popular, na política interna), sendo este o seu sentido nuclear para a nossa cultura; dotado por seu caráter relacional, de intermediação, intercâmbio e integração plural, multifacetada, complexa, contraditória e conflituosa entre as classes sociais (LAIBIDA, 2016).

Laibida (2016) assinala que o futebol no Brasil é um marco de individualização e possibilidade de expressão individual, muito mais do que expressão de coletividade. É com base nesse foco dialético entre individualização e coletividade que, para o autor, o futebol brasileiro permite exprimir o conflito presente entre destino impessoal versus vontade individual; este é um simulacro da própria sociedade brasileira onde o futebol focaliza e dramatiza, pois, mesmo apresentando vontades individuais, é um esporte regido por leis impessoais, apresentando fatores imprevisíveis que podem dar a vitória para uma equipe considerada menos apta para ser a vencedora, ou seja, não há um modo de prever com segurança uma relação direta (racional) entre os meios e os fins. A possibilidade de expressão individual, abordada pelo autor, dá aos indivíduos, não a unidade da identidade, porém, o ingresso para novas possibilidades de dispersão: aí está o jogo expresso nas lutas por Foucault. É justamente na imprevisibilidade do jogo que o futebol deve ser visualizado, distante do seu caráter funcional, pois, só assim, é possível envolver a dimensão social, política e econômica com as suas tensões.

Como o futebol não escapa das relações com o local, nem das especificidades das suas formas de transplantação, se espalha sendo absorvido, as vezes em seu caráter integrador e de coesão social, outras, enquanto um evento na dinâmica social, com base nas conquistas e nos heróis ou, mesmo, por seu papel civilizador no processo de modernização da sociedade (Huizinga, 2004; Corbin, 2001; Caillois, 1990), vem sendo até enfatizado como um redutor das desigualdades sociais e econômicas, visto que há interação entre indivíduos de várias origens étnicas e sociais. Nesses diversos sentidos o futebol se espalha, sua importação é passível de várias histórias. Uma vez que o jogo de futebol não é imposto, sobretudo, de cima para baixo, nas dinâmicas em que imerso ele é emulado e incitado a suar a camisa com o jogo local.

No Paraná essa importação ganha relevo a partir da primeira década do século XX, período em que o futebol já tinha seu território constituído em âmbito ocidental, já atendia ao processo de civilização, tornando-se símbolo da superioridade dos países do centro europeu e se arrolava em fator de integração social e delimitador de identidades. Os primeiros adeptos surgiram no município de Ponta Grossa, em 1908, influenciado pelo inglês Charles Wright que 
- atuava nas construções de linhas férreas - trouxe consigo todos os materiais necessários à prática do esporte. Em 1909, surgiu o primeiro clube paranaense, o "Coritibano Foot-Ball Club", criado por meio de uma organização dos alemães. A ata de fundação data do dia 12 de outubro de 1909, dia do primeiro amistoso reconhecido no Estado do Paraná, entre o atual Coritiba e um time de trabalhadores ferroviários do município de Ponta Grossa. Logo, organizaram-se novos clubes, de antemão ligados às famílias predominantemente alemãs e tradicionais na formação do estado ${ }^{3}$. (LAIBIDA, 2016).

Em sequência, surgem no Estado vários clubes relacionados ao trabalho, que operavam no âmbito da empresa, aproximando o jogo do trabalho. Citam-se o "Paraná Sport Club", fundado em 1912 pelos funcionários ingleses da American Brazilian Engineering e do London Bank, o Operário Ferroviário ligado aos trabalhadores da ferrovia, o Clube Atlético Ferroviário, da Rede Viação Paraná-Santa Catarina, o Rio Branco, relacionado às atividades portuárias, entre outros. Para além das lógicas operárias, as questões de bairro também são fundantes, junto com a cultura masculina da bebida e a confirmação da solidariedade que define um território, sobre o qual o clube exerce sua influência cultural e em seu interior ordena as relações sociais, caso do Savóia Futebol Clube, que posteriormente virou o Esporte Clube Pinheiro; do Britânia Sport Club, fusão de dois times de bairro, que, posteriormente, unido a outras equipes fundou o atual Paraná Clube; nessa mesma lógica seguiu o América Foot-ball Club e o Internacional que desembocaram no atual Clube Atlético Paranaense (LAIBIDA, 2016).

Sobre o "Internacional Foot-Ball Club", vale lançar alguns nomes de destaque da elite curitibana, tais como o de Joaquim Américo Guimarães, que, junto com outros destaques sociais, fundou o "Club Sportivo", cuja sede era no Jóquei Clube de Curitiba. Nesse rol encontravam-se ainda, Guimarães, Agostinho, Ermelino de Leão Júnior, membros da família Mader, Arouca, Sigel e outras, também, membros fundadores do Graciosa Country Club, espaço que representava o sinônimo de poder e articulação social e política (MACHADO; CHRESTENZEN, 2005).

Apenas para apresentar um dos cenários das relações que envolviam as elites locais e suas relações de parentesco no período de gestação dos clubes de futebol do Paraná, vamos citar um campeonato representativo para a história do futebol estadual, realizado em 1915, foi o primeiro organizado pela Liga Sportiva Paranaense e na equipe vencedora estava o primeiro artilheiro do estado, o jovem Ivo de Abreu Leão, que, com apenas dezessete anos, entrou para a história. Sendo esse rapaz neto de Agostinho Ermelino de Leão, que foi presidente da

\footnotetext{
${ }^{3}$ Para maiores informações sobre a formação dos clubes de futebol em Curitiba-PR, ver LAIBIDA, 2016.
} 
província e desembargador, bisneto de Manuel Antônio Guimarães, camarista de Paranaguá e vice-presidente da província, sobrinho de Cândido Ferreira de Abreu, que ocupou o cargo de prefeito de Curitiba; também, sobrinho do historiador Ermelino de Leão.

O resumo com a descrição da organização dos clubes de futebol citados nos parágrafos acima não será facilmente compreendido pelo espectador do camarote ou da arquibancada, isso porque diante de um jogo espera-se ter um vencedor ou perdedor e o que temos com essa breve síntese que aponta para a organização, fundação, união e dissolução de clubes de futebol, é um engendramento complexo do jogo social e suas relações entre o global/local e a tensão pertinente ao jogo de cada clube. As vitórias e derrotas que aparecem a princípio não demarcam queda ou ascensão, são apenas circunstanciais acidentais, inesperadas, imprevisíveis que não demarcam continuidade, mas, sim, um combate permanente e dinâmico.

As datas especificadas, a organização da fundação dos clubes, as famílias e empresas envolvidas nos reportam à cultura da rivalidade local, mas também a um rito de integração, à tradição popular do desafio e da façanha. A restrição do jogo de futebol às fidelidades e concepções morais elitistas dilui-se à medida que o jogo se espalha e que a dinâmica do tempo/espaço se emaranha em suas relações. A própria inserção da lógica econômica do nosso sistema cultural de relações sociais condiz com a aceitação do papel do dinheiro no futebol, com a profissionalização, com a inserção da aposta e do lucro. Esse é o enfretamento diante da bola de futebol; feitas com base na representação do Icosaedro truncado, não admitindo linearidades e evoluções, mas, sim, mutilações, cortes, troncos que formam múltiplos gomos de diferentes conceitos, formas e temas.

No campo de futebol onde cinge a dinâmica da bola, ela não desliza em um percurso coerente, contínuo e certeiro. A bola é atirada no corpo a corpo dos que a enfrentam, os indivíduos lutam para chutá-la e atingirem seus objetivos, para alcançarem suas metas, realizarem seus sonhos; para tal, o drible é uma estratégia que confunde os caminhos possíveis, o beque também faz parte das táticas de que se lança mão para alcançar um fim e é nessa imprevisibilidade social que se garante a previsibilidade das ações e a construção de uma pesquisa rica, cuja temática do futebol aparece como fascinante. Contudo, é um jogo de enfrentamento e empoderamento e por que os consagrados donos da bola têm que ser os responsáveis pelo gol? O interessante no jogo de futebol é que o resultado final ninguém sabe dizer. O mesmo ocorre com nosso texto, que, com a previsibilidade afastada, com os dados empíricos do futebol paranaense em mãos, destaca que o gol pode ser contra, a bola fora e o lance estar impedido. Como Foucault (1984, p.26) afirma, escrever é antes de tudo "se apoderar de um sistema de regras, é fazê-las entrar em um outro jogo e submetê-las a novas regras". Isso 
quer dizer que o próprio trabalho interpretativo do pesquisador constrói um jogo de novos sentidos e significações, deslocando o resultado do seu lugar sagrado, alternando e invertendo o sentido do jogo.

\section{Bola fora: resistências e transformações no campo de jogos}

Iniciamos nosso texto com a assertiva de que o Estado do Paraná é configurado por uma ordem dominante central que constrói e mantém espaços de dominação. De acordo com Oliveira (2001), o Paraná, quando emergiu enquanto província do Império, tinha o papel de se modernizar, como de fato incidiu em algumas esferas; contudo, na conjuntura que está relacionada ao poder não é possível perceber notáveis alterações; o que se observa é o poder desmembrado nas mãos de famílias tradicionais, as quais vão se reproduzindo nas principais instituições do estado. A dominação dos grupos familiares é expressiva, o que determina a construção de permanências no poder e estigmatiza o presente com relações arcaicas.

Partindo desse fio condutor, o espaço que baliza as relações concernentes ao futebol não fugiria a regra. Desse modo, as conexões e os poderes sociais e políticos acumulados ao longo de diversas gerações fundamentariam o domínio dos grupos tradicionais, mantendo-os no poder. Não questionamos que isso é fato em várias esferas da dinâmica nacional e, em especial no Paraná, onde a própria atuação da elite no aparelho do Estado, com suas relações coloniais, descaracterizam as normas e sistemas burocráticos e favorece direta e indiretamente o controle do fluxo de informações, capitais e privilégios essenciais para a sua reprodução.

Contudo, toda história é a mesma história? As relações sociais são engendradas com base nos mesmos tecidos e centros geradores? Todo poder se mantém? Essas questões direcionam à dimensão crítica da reprodução de concepções em muitos estudos, em que a história que emerge com base na pesquisa da uma genealogia pode ser interpretada diante da afirmação de Foucault (1984, p.17), como "sistemas de submissão: não a potência antecipadora de um sentido, mas o jogo casual das dominações". A grosso modo o poder aparece como uma maquinaria de reprodução da ordem, como uma camisa de forças, como um processo contínuo, teleológico e evolucionista. Será que essa ordem se reproduz nesse campo de estudo? Será que outras perspectivas não são possíveis? É o que veremos, ou não, mais adiante.

Para organizar nossa compreensão dos dados empíricos assinalamos as configurações de poder no interior dos quatro clubes de futebol em Curitiba, capital do Paraná, já mencionado no início do texto, por meio do mapeamento dos seus principais dirigentes e suas relações sociais com as elites locais. E observamos que indivíduos que estão à margem da perspectiva 
genealógica local, na periferia dos campos políticos e sociais definidos por essas elites, abarcam o poder no futebol contra uma lógica de dominação que parecia firmada pelo acesso às instituições sociais determinantes nesse espaço. Mesmo com menor poder de barganha, as estratégias sociais permitem que novos agentes, como os empresários, entrem em cena, por intermédio de táticas que rompem com velhos paradigmas. É o gol contra, a surpresa em relação aos estudos que apontam que o Estado do Paraná se caracteriza por uma história em que a classe dominante, organizada por grupos familiares específicos, mantém sua hegemonia presente até os dias atuais.

Em 1933, a Federação Paranaense de Desporto (FPD) aderiu à diligência nacional especializada, denominada Federação Brasileira de Futebol (FBF), na tentativa de se profissionalizar e de participar das tomadas de decisões e possibilidades de jogos nacionais, deixando de lado a Confederação Brasileira de Desportos (CBD). Entretanto, a CBD assediava a FBF com o objetivo de fazê-la retornar à mesma, assim como agia com a própria FDP, para seu reingresso na instituição. Havia uma discussão muito grande sobre a profissionalização do futebol brasileiro, dentro de um órgão regulador dos interesses exclusivos do futebol.

O órgão que regula as relações do futebol no estado é a Federação Paranaense de Futebol (FPF), que foi fundada em 1937, após o aparecimento de vários movimentos realizados com o propósito de organizar o futebol no Paraná como um todo, pois a primeira organização de futebol no Paraná, a Liga Sportiva Paranaense (LSP), fundada em 1914, era bastante elitizada e centralizada na capital; entretanto, dissidentes da Liga que se sentiram lesados em resultados criaram o seu concorrente, que era a Federação Paranaense de Desportos (FPD). A LSP transformou-se na Liga Curitiba de Futebol (LCF), administrando o futebol em Curitiba; já a FPD administrava o futebol no Estado. Mesmo com a criação da FPF em 1937, somente em 1941 a FPD e a LCF foram extintas e a FPF, desde essa data, tornou-se a maior entidade do futebol paranaense. 


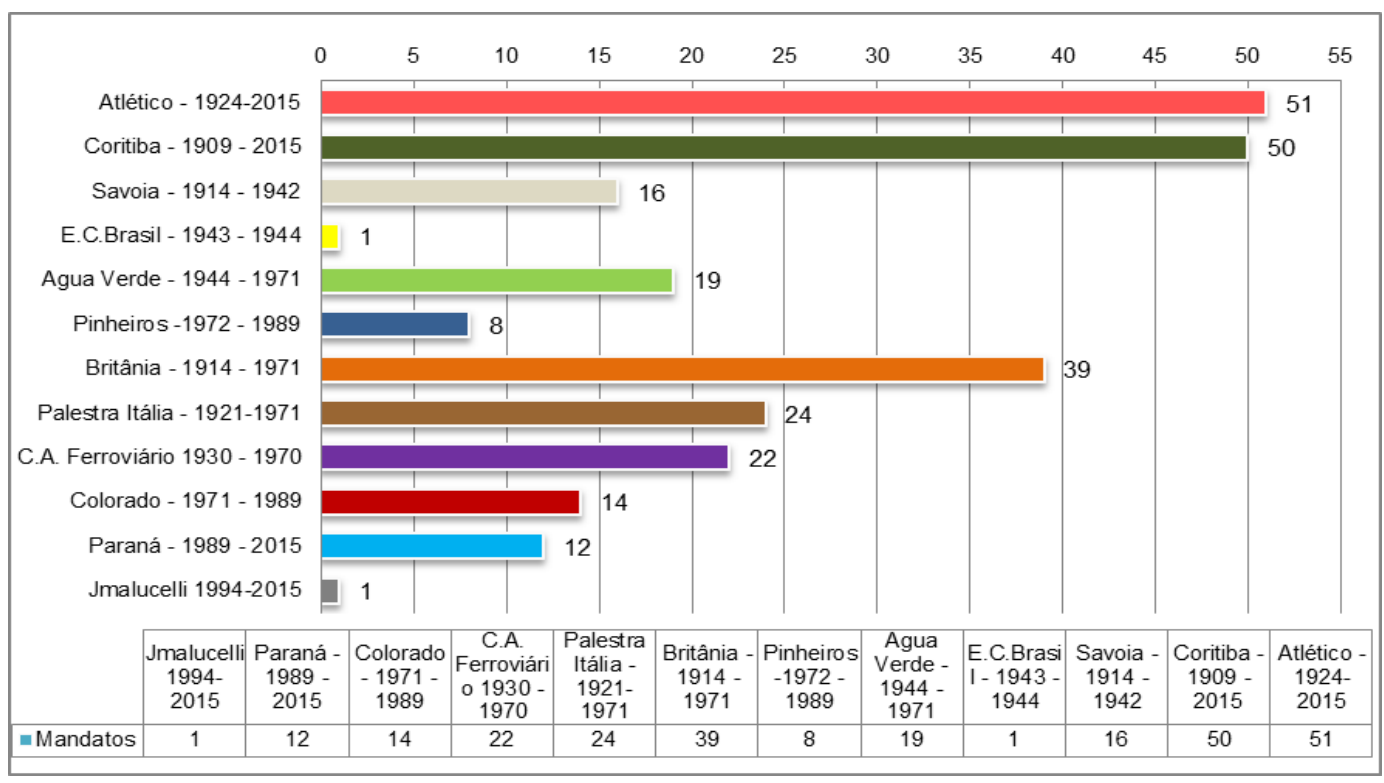

Fonte: MACHADO, H.I. CHRESTENZEN.L.M. Futebol do Paraná: 100 anos de história. Curitiba-PR, 2005 e arquivos do Paraná Clube ${ }^{4}$. ORG. (LAIBIDA, 2016)

Gráfico 1- Número geral de presidentes dos clubes ${ }^{5}$

Podemos compreender, analisando o gráfico acima, que havia uma rotatividade muito grande dos dirigentes dos clubes profissionais do futebol paranaense, tendo média geral menor do que dois anos por mandato, oscilando remandados. O futebol, por muitos anos, foi pouco profissional, servindo de "trampolim" político, "paixões" e "recreação". As federações eram informais até quase a década de 1940, e não havia remuneração. Eleições para os dirigentes dos clubes de futebol paranaense existiam desde o início, porém, elas ocorriam de forma muito "direcionada" e "parcial", organizada pelos dirigentes dos próprios clubes. Ocorriam de modo informal, na "calada da noite", sem mesmo haver divulgação na imprensa ou ata de formalização. Os modelos eleitorais mais abrangentes, com participação de conselheiros, são recentes, com participação de sócios e com eleições "abertas".

$\mathrm{Na}$ atualidade, os clubes têm estatutos elaborados por seus conselhos, preestabelecendo prazos de eleições. Criaram-se os clubes empresas, sendo pioneiro o estado do Paraná, com o JMalucelli S.A, em 1994. Os dirigentes dos clubes, principalmente, nas primeiras sete décadas, detinham papéis sociais importantes, necessitando constantemente deixar responsabilidades dos clubes em segunda opção, causando os desligamentos frequentes. O futebol não era tão

\footnotetext{
${ }^{4}$ Localizada na Av. Pres Kennedy, 2377 - Água Verde, Curitiba - PR, 80610-010.

${ }^{5}$ O Paraná é um clube de fusões; com exceção do Atlético, Coritiba e Jmalucelli, os demais clubes deram por diversas fusões o atual Paraná Clube.
} 
"vantajoso" economicamente como hoje, pois incentivos de patrocinadores, Estado e torcida não existiam; o que se tinha eram elites ou clubes profissionais que administravam conforme seus próprios interesses, possibilidades e paixões. Sempre que havia crises internas, havia dificuldades de administração, fossem essas crises de títulos, financeiras, conflitos de interesses. Já houve períodos em que três presidentes assumiram em um só ano.

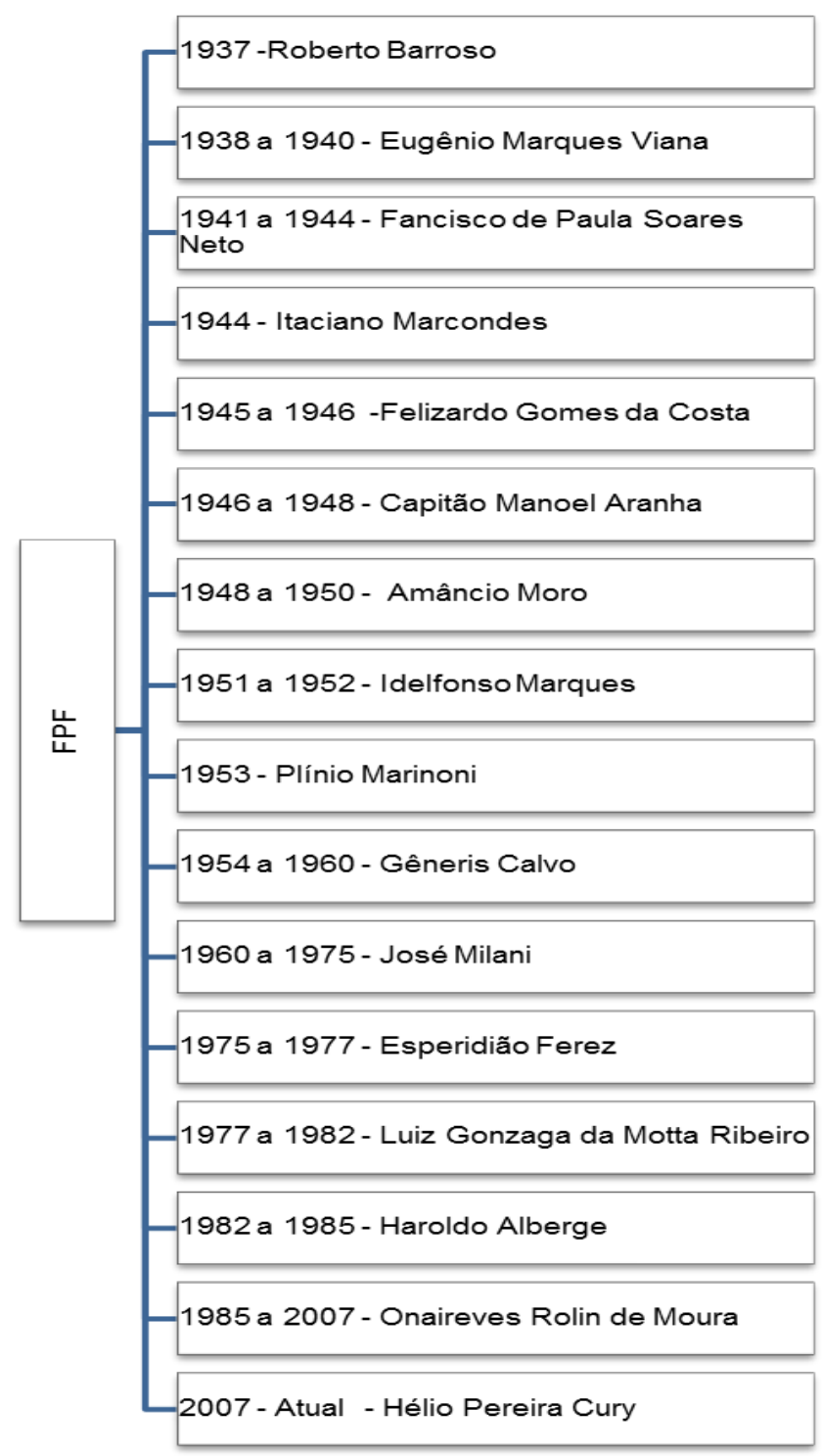

Fonte: Site Oficial da Federação Paranaense de Futebol ${ }^{6}$ Org. Laibida (2016)

Gráfico 2 - Presidentes da FPF

O primeiro presidente da FPF, em 1937, foi o jornalista Roberto Barroso. Tinha estreita ligação política com o governador Bento Munhoz da Rocha Neto. Foi um dos responsáveis pelo criação da FPF. Eugênio Marques Viana assumiu a presidência de 1938 a 1940; oriundo da elite

${ }^{6}$ http://www.federacaopr.com.br (acessado em 20/04/2013). 
econômica do Paraná, era comerciante e já havia presidido o Clube Atlético Paranaense em 1934. Em 1941, foi eleito o Coronel Francisco de Paula Soares, um médico do Exército que presidiu a FPF até 1944. Foi senador pela UDN e Secretário da Fazenda. Em 1944, assumiu a presidência da Federação Itaciano Marcondes, tendo permanecido no cargo somente no ano eleito. Foi um dos responsáveis pela unificação da LCF com a Federação Paranaense de Futebol, dividiu o comando da entidade com Eugênio Marques Viana, entre 1938 e 1940. Também foi presidente do Atlético cinco anos depois, ficando até 1950. Nos dois anos seguintes, a presidência ficou a cargo de Felizardo Gomes da Costa ${ }^{7}$, filho de Francisco Gomes da Costa e da professora Maria Arminda do Nascimento Costa, estudou na engenharia civil na Universidade Federal do Paraná. Muito jovem foi nomeado funcionário do Telégrafo Nacional. Depois de ter alcançado várias promoções, mudou-se para Curitiba, onde trabalhava e estudava. Chefiou a Delegacia do Serviço de Patrimônio da União, no Paraná. Ocupou o posto do Secretário de Viação e Obras Públicas e da Fazenda e a presidência do Banco do Estado. Em 1946, foi eleito presidente da FPF o gaúcho Capitão Manoel Aranha, com apoio declarado da imprensa e dos clubes da capital. Filho do Coronel Euclides de Sousa Aranha, teve dez irmãos, entre eles, Osvaldo Aranha.

Na segunda metade do século XX, Ildefonso Marques assumiu a presidência da FPF no biênio 1951/1952. Jurista, chegou a exercer o cargo de desembargador do Tribunal de Justiça do Paraná. Foi, ainda, professor de Direito Penal da Faculdade de Direito da Universidade Federal do Paraná e na Pontifícia Universidade Católica; em ambas, exerceu o cargo de diretor. Plinio Marinoni foi presidente do Britânia, árbitro e presidente da FPF em 1953; teve como irmão Flavio Marinoni, que foi artilheiro e jogador do Britânia no fim da década de 1920. De 1954 a 1960, Generis Calvo assumiu a presidência. De 1960 a 1975 assumiu José Milani, dentista de formação, fazendeiro, empresário e cartola. De 1975 a 1977, presidiu a FPF Esperidião Ferez, presidente de clube de xadrez, médico e coronel reformado. Em 1977, assumiu Motta Ribeiro, formado em Direito e proprietário do Tabelionato 9. O ano de 1982 foi do contador Haroldo Alberge ${ }^{8}$, representante do futebol amador, numa eleição atípica, com empate, contra Antônio Carlos de Mello Pacheco; ganhou a eleição porque era o mais velho dos dois candidatos. De 1985 a 2007, o presidente foi Onaireves Nilo Rolim de Moura ${ }^{9}$, de

\footnotetext{
${ }^{7}$ Jornais “O Dia” de 08 e 09/02/1945

${ }^{8}$ Enfrentava o otimismo de Milani, ex-presidente, porém, o mesmo acabou nem se candidatando.

${ }^{9}$ Www.paranaonline.com.br, matéria jornalística de 07/11/2007 (acessado em 11/12/2015), Ganhou a eleição contra com o então presidente Harold Alberge e com o diretor do Colorado e político Aziz Domingos. Venceu e retomou de imediato a construção do Pinheirão, que se transformou no seu principal "cavalo de batalha". Às vésperas da Copa do Mundo de 86, Moura foi nomeado diretor de relações públicas da CBF - um cargo que nunca existiu, segundo o relato do próprio cartola àquele período. Ele acabou envolvido no chamado "escândalo do
} 
Chapecó, que chegou a Curitiba na juventude. Presidiu o Atlético de 1982 a 1985 e, depois, a Federação Paranaense de Futebol, onde permaneceu até 2007. Depois, em carreira política, foi cassado e preso por desvios fiscais.

Atualmente, é presidente Hélio Pereira $\mathrm{Cury}^{10}$, que passou por cargos políticos comissionados, além de ter sido atleta, técnico, diretor e conselheiro de várias equipes de futebol na capital. Reelegeu-se em 2015 por mais quatro anos, numa eleição bastante conturbada contra Ricardo Gomyde. A eleição parou na justiça a pedido dos clubes da capital, devido à falta de circulação pública do edital nos meios de comunicação. Porém, Hélio Cury, com apoio dos clubes do interior, derrubou a liminar e assumiu em definitivo ainda em 2015.

O poder político, econômico e social esteve muito presente na FPF. Dos dezesseis presidentes da Federação, quinze ${ }^{11}$ detinham poder político (relação direta com os poderes executivo, legislativo ou judiciário) ou econômico (grandes empresários ou comerciantes), que os configuravam nas relações de poder do Paraná; apenas um ${ }^{12}$ presidente eleito pode ser configurado como entrante. Justamente por esse fato, essa modalidade de futebol cresceu e imergiu na esfera global, com a complexidade do processo de globalização presente em todas as esferas da sociedade, ocasionando várias mudanças estruturais que, muitas vezes, perpassam

videoclip", uma acusação de extorsão feita pelo publicitário Rogério Steinberg (falecido no mesmo ano) que atingia diretamente o então vice da entidade Nabi Abi Chedid. Afastado do poder nacional, o presidente da FPF voltou-se para a política regional.A primeira parte da gestão de Moura foi voltada para os clubes menores e entidades amadoras. Com a força destes no colégio eleitoral, o presidente conseguiu se reeleger na FPF, e em 1990 foi eleito deputado federal. Às vésperas do impeachment de Fernando Collor, em 92, promoveu um jantar em homenagem ao então presidente da República. Na votação, optou pela saída de Collor. No ano seguinte, foi cassado por quebra de decoro parlamentar. Moura seguiu presidindo a FPF, mantendo um bom relacionamento com o presidente da CBF, Ricardo Teixeira - não sem alguns desentendimentos. Em 1998, entretanto, novo escândalo: ele foi destituído do cargo pela Justiça, por causa de uma dívida de R\$1,2 milhão com a Prefeitura de Curitiba. Era falta de pagamento do IPTU. Foram nomeados dois interventores para a Federação - um para a parte jurídica e outro para o futebol. Mas o período de afastamento durou pouco: outras irregularidades foram descobertas e os interventores também foram afastados. Onaireves Moura voltou à FPF, saindo definitivamente apenas em 2007. ${ }^{10}$ www.federacaopr.com.br/predidente (acessado em 05/06/2015).

${ }^{11}$ Roberto Barrozo, aliado de Bento Munhoz da Rocha Neto; Eugênio Vianna, um dos maiores comerciantes de Curitiba, aliado nos negócio da família Leão (Ermelindo de Leão) e fundador do Clube Atlético Paranaense e Presidente do Atlético, junto com Arcésio Guimarães, Coronel Francisco de Paula; Alta patente do Exército Brasileiro e Senador pela UDN, Presidente do Britânia; Itaciano Marcondes, Presidente do Atlético, Presidente da Cohapar, amigo pessoal da família Guimarães; Felizardo Gomes da Costa, Presidente do Banestado; Capitão Manoel Aranha, Presidente do Atlético, oficial do Exército e político (concorreu a prefeitura de Curitiba contra Ney Braga); Amâncio Moro, Presidente do Coritiba, grande empresário, Prefeito de Curitiba (aliado de Bento Munhoz da Rocha Neto); Idelfonso Marques, Desembargador; Plínio Marinoni, Presidente do Ferroviário, Dirigente da Rede Paraná - Santa Catarina, empresário; Gêneris Calvo, Chefe da Estação Naval de Paranaguá; José Milani, maiores fazendeiros do Estado; Luiz Motta Ribeiro, cartorário; Onaireves Nilo Rolim de Moura; empresário e deputado federal; Hélio Cury, vice-presidente de Oinareves, secretário municipal de Mauricio Fruet e apoio político de Gustavo Fruet.

${ }^{12}$ Haroldo Alberge, ligado ao Futebol Amador (onde conseguiu votos para eleição). 
pela dicotomia entre o bem e o mal; nessa esfera estão os clubes paranaenses (Atlético, Coritiba, Paraná e JMalucelli), com intensa presença dos meios de comunicação e do marketing.

Nesses termos a lógica empresarial no futebol paranaense emerge dentro do próprio confronto e da dispersão das forças dominantes que estavam em luta. Tal reflexão implica afirmar que os novos sujeitos sociais construíram seus espaços na dependência da existência dos espaços anteriores, contudo, se apoderaram das regras e tomaram os lugares daqueles que as utilizavam. O lugar, dominado em grande parte pelas famílias que se perpetuam nas esferas de poder político e econômico ao longo de gerações na esfera do futebol, foi pervertido, modificou-se com o tempo, saiu do "amadorismo" para a profissionalização.

\section{Quem são os donos do jogo afinal?}

Como observamos com a pesquisa de campo, as origens das relações não determinaram as formas atuais do empoderamento no espaço dos jogos de futebol no Paraná. As tramas sociais envolvidas nas distintas relações sociais espaciais, influenciadas pelos contornos locais e globais, permitiram a produção de novos sentidos, práticas, criaram lugares passíveis de serem habitados por diferentes indivíduos. Assim, apontamos como a estrutura nuclear do jogo de futebol concebe o funcionamento da sociedade enquanto resultado de incontáveis e variados afrontamentos, transgressões e dispersões de acontecimentos que se sobressaem em meio às disputas engendradas nesse espaço em que o tradicional cede lugar ao novo, uma vez que os dirigentes dos clubes em questão, como atestamos no Paraná, estão perdendo os seus espaços para novos indivíduos.

Com a profissionalização do futebol, o chamado trio de ferro da capital (Atlético, Coritiba, Paraná) e o JMalucelli trilham caminhos muito próximos de administração clubística com seus dirigentes. O JMalucelli é o primeiro clube empresa do país e hoje se mantém em ascensão, além de deter, em poucos anos, boas participações no estadual e um título nacional, série "C", em 2000, quando se chamava Malutrom. A ideia do futebol como trampolim político é uma verdade no futebol semiprofissional e amador; porém, no futebol profissional, ainda que essa possibilidade exista e seja real, o inverso também é verdadeiro: a política usada como um trampolim para o futebol. Atualmente, esses clubes são em maioria, organizados por profissionais da "bola", empresários graduados na "arte" de conquistar espaço e poder, de agregar bens materiais. O Paraná conquistou, em um período de seis anos, o que vários clubes de antigas fusões não haviam conquistado juntos em décadas. Isso rompe com um espaço de 
afetividade e "tradicionalidade", dando espaço à racionalidade valorativa, como cunha o modelo weberiano, voltado aos fins e à profissionalização.

Ainda que haja equilíbrio em termos qualitativos ${ }^{13}$ entre as elites tradicionais e novos indivíduos na direção do nosso futebol, fica bastante explícito que algumas ocupações se destacam na formulação e construção dele, como os empresários, que se configuram no poder, em especial no futebol contemporâneo, pós 1970, ou seja, no futebol moderno e globalizado, em que ganharam ainda mais espaço e destaque. Mas isso passou de uma necessidade para uma possibilidade, ou seja, o futebol paranaense nasceu do poder político de famílias tradicionais, que se mantêm tradicionais, mas não necessariamente tradicionais nos clubes, dividindo, muitas vezes, a atenção com os empresários.

Desse modo, afirmamos que não há uma regra do poder, que o espetáculo, o aparecer, o vir à cena do jogo é a novidade, não existindo uma essência que estaria escondida nos vestiários e só apareceria no final do segundo tempo, por um suado esforço de interpretação. $\mathrm{O}$ jogo, assim como as relações de poder, existem enquanto acontecimento, surgem de regras em que é possível se jogarem inumeráveis partidas, com várias interpretações possíveis e variadas combinações dos mesmos elementos, que se percebe de diferentes modos. Essa é a forma de conceber o funcionamento da sociedade, de figurar um modo de ver o mundo e seus inúmeros afrontamentos entre forças na dinâmica e na dispersão de acontecimentos.

Não existem donos legítimos da bola, essa é uma relação mediada no jogo, que se constrói com a criatividade e com as reações que impedem ou impulsionam os grupos interessados. Isso porque as relações são feitas de enfrentamentos constantes, em que os participantes e interessados tentam alianças ou a captação do domínio das regras ou, ainda, vislumbram a possibilidade de burlá-las ou usá-las contra o oponente. Mesmo o jogo do empoderamento no futebol, utilizando-se de regras já conhecidas e determinadas, é jogado a cada partida, por isso é descontínuo, não repetível, não imaginado no início das partidas. Não desconhecemos que as ações individuais são importantes,

Existem, sim, sujeitos que jogam com mais força e são mais decisivos que outros, existem os indivíduos que abrem possibilidades para outros, porém, até esses precisam do conjunto das interações, isso porque a dinâmica social do empoderamento e do poder jogar exige a relação com o todo e com os lugares, sem os outro não haveria jogo. O futebol paranaense destaca uma relação de forças que se inverte, apresenta poderes confiscados na área singular dos acontecimentos (FOUCAULT, 1984).

\footnotetext{
${ }^{13}$ Não contabilizando aqueles que não tiverem reconhecidas profissões ou ocupações.
} 


\section{Referências bibliográficas}

ALBUQUERQUE JR., Durval Muniz de. A história em jogo: a atuação de Michel Foucault no campo da historiografia. In: Anos 90 - Revista do Programa de pós-graduação em História. V.11, n 19, UFRGS, 2004.

CAILLOIS, Roger. Os jogos e os homens. Lisboa: Cotovia, 1990.

CORBIN, Alain. A história dos tempos livres. Lisboa: Teorema, 2001.

DA MATTA, Roberto. Universo do futebol: esporte e sociedade brasileira. Rio de Janeiro: Edições Pinakotheke, 1982.

FOUCAULT, Michel. Microfísica do poder. $4^{\mathrm{a}}$ ed. Rio de Janeiro: Graal, 1984.

HUIZINGA, Johan. Homo ludens. 5a ed. São Paulo: Perspectiva, 2004.

LAIBIDA, Luiz Demétrio Janz. Raposas e outsiders no futebol paranaense, um estudo sobre genealogia e poder. Curitiba - PR: Instituto Memória, 2019.

MACHADO, H.I.; CHRESTENZEN.L.M. Futebol do Paraná: 100 anos de história. CuritibaPR: Digitus, 2005.

OLIVEIRA, R. C. O Silêncio dos vencedores: genealogia, classe dominante e Estado no Paraná. Curitiba - PR: Moinho do Verbo, 2001.

OLIVEIRA, R. C. Famílias, poder e riqueza: redes políticas no Paraná em 2007. Sociologias, Porto Alegre, ano 9, no 18, p. 150-169, jun/dez.2007. 